This item was submitted to Loughborough's Research Repository by the author.

Items in Figshare are protected by copyright, with all rights reserved, unless otherwise indicated.

\title{
Training and assessment of physiotherapy assistants
}

PLEASE CITE THE PUBLISHED VERSION

https://doi.org/10.1016/S0031-9406(05)66108-1

PUBLISHER

Elsevier () Chartered Society of Physiotherapy

VERSION

VoR (Version of Record)

\section{PUBLISHER STATEMENT}

This work is made available according to the conditions of the Creative Commons Attribution-NonCommercialNoDerivatives 4.0 International (CC BY-NC-ND 4.0) licence. Full details of this licence are available at: https://creativecommons.org/licenses/by-nc-nd/4.0/

\section{LICENCE}

CC BY-NC-ND 4.0

\section{REPOSITORY RECORD}

Parry, Ruth, and Catherine D. Vass. 2019. "Training and Assessment of Physiotherapy Assistants". figshare. https://hdl.handle.net/2134/32707. 


\section{Training and Assessment of Physiotherapy Assistants}

\section{Ruth Parry Catherine Vass}

\section{Key Words}

Physiotherapy assistants, assessment, training, task delegation.

\section{Summary}

This paper discusses some of the issues relevant to the role and training of physiotherapy assistants. It describes the processes of role definition, assessment and training of one particular assistant, developed in the context of a larger research study. A small survey of senior physiotherapists' views on task delegation, training and working with assistants was conducted, using semistructured interviews. The method and findings are described; broad agreement between the physiotherapists was found. $A$ training and assessment package was then developed and implemented. The training was specifically related to treatment of the upper limb of acute stroke patients.

While delegation to assistants is part of everyday practice for many physiotherapists and the training of these staff a professional obligation, the structure and support to do so are often lacking. In the context of the description of a particular case, this paper provides some insights and points of interest for clinicians involved in training and task delegation to assistants.

\section{Introduction}

Physiotherapists who work with assistants have professional obligations to train them adequately and to delegate responsibly. However, such obligations are not easy to meet; other tasks compete for our time and there is much uncertainty concerning how we can best train assistants and what their role should be. This report describes one way in which these issues were tackled. The process of role definition, assessment and training of an assistant within a broader research project are described, and some insights and points of interest for physiotherapists are discussed.

Physiotherapy assistants make an important contribution to the care of patients (Walker, 1995; CSP, 1989). An increase in the breadth and complexity of tasks delegated to assistants has occurred as physiotherapy caseloads have grown and as the National Health Service has undergone organisational change. To give a high quality service, assistants need to be well trained (Walker, 1995).

The main aim of a research trial currently in progress in Nottingham is to evaluate the effects of additional upper limb treatment for stroke patients during their early rehabilitation. One aspect of this trial is a comparison of physiotherapy administered solely by a qualified physiotherapist with that partially administered by an assistant. Effects will be measured in terms of patients' motor skills and functional abilities. Ethical approval for the trial was sought and granted.

Patients are randomly assigned to one of three groups - 'control', 'physiotherapy' and 'assistant' - who all continue to receive 'normal' physiotherapy from the clinical staff. The control group receives no additional treatment. The physiotherapy group receives additional treatment from the research physiotherapist. Assistant group patients receive additional treatment from an assistant; treatment programmes for this group being devised by the research physiotherapist after a clinical assessment. These programmes consist of activities chosen from a treatment manual designed by the research physiotherapist for use in the study. The assistant is supervised regularly and the treatment programmes are re-evaluated and adjusted by the research physiotherapist. On completion of the study, outcomes of the different groups will be compared and an economic evaluation undertaken.

The work reported in this paper took place during the preparation phase of the study. The constraints of the study are such that the physiotherapist is not free to choose which patients the assistant treats. The emphasis of this report is thus on choices about types of techniques taught and undertaken rather than types of patients treated by assistants.

\section{Review of the Literature}

The majority of articles concerning assistants which are published within the physiotherapy literature consist of rules or guidance given by professional bodies (eg New Zealand Society of Physiotherapists, 1981; CSP, 1994a). Other publications describe the role and training 
of assistants in the context of such guidance (Lupi-Williams, 1983).

There are similarities between the roles of assistants in the United States, Canada, New Zealand and the United Kingdom. They do not perform initial assessments or make major changes to treatment programmes, nor do they apply highly specialised techniques. In these countries assistants must work under supervision of a qualified, responsible physiotherapist who monitors and reassesses patients.

Areas of discrepancy between countries include whether assistants contribute to progressing treatments, ruled as part of their role in the US but not elsewhere: Involvement in applying electrotherapy also varies.

The need to train assistants adequately for their role is stressed by professional bodies. In the United Kingdom and most of Canada, training is 'in-house' or 'on-the-job'. In the United States, 'physical therapy aides' are trained in-house, in contrast to 'physical therapy assistants' (PTAs). PTAs attend two-year college programmes approved by the American Physical Therapy Association. This more formalised training, available since 1967, developed as a result of an 'increased need for physical therapy services' (Lupi-Williams, 1983). It was felt that use of trained assistants would enable physical therapists to practise more effectively. The main difference between 'aides' and PTAs is that the latter not only learn treatment skills but 'develop understanding for the use of these techniques' (Lupi-Williams, 1983). There are developments in Canada (McNeil et al, 1990) and the United Kingdom (in the form of National Vocational Qualifications) towards more formalised and academic training of physiotherapy assistants.

Professional attitudes to assistants have been investigated using survey methods. With respect to professional bodies' guidance on appropriate delegation, surveys have found few substantial differences between this guidance and actual practice (McNeil et al, 1990; Robinson et al, 1994). McNeil and colleagues also investigated Canadian physiotherapists' opinions on future development of training and found that a formal system similar to but shorter than the American programme was favoured.

Saunders (1995) investigated the roles, tasks, concerns, and training of assistants in out-patient departments in England. She suggests that assistants' potential is 'not being fully tapped' because of the lack of a 'scientific approach to task delegation', and that investment in training brings improvement in both cost effectiveness and quality of care.
There do not appear to be any published studies comparing quality and effectiveness of treatments between qualified physiotherapists and nonqualified staff. The only such report which was found during the writing of this paper is an unpublished study undertaken in Sheffield (Samworth, 1995).

Occupational therapy literature shows a similar pattern. Guidelines on the role of assistants are published by professional bodies (College of Occupational Therapists, 1996); there have been surveys of professionals' opinions (Strickland, 1993), and discussion papers (Hirama, 1994). Mead et al (1985) described the rationale and content of a training programme for assistants, but experimental research is lacking.

Published studies within the related field of nonqualified nursing staff have considered the effect of staff training level on patient care. McKenna (1995) reviewed research concerning the effect on quality of care of skill mixes with differing proportions of qualified and non-qualified staff. Implementing training programmes, and the processes of delegation and ongoing supervision were found to be costly and led to decreases in qualified nurses' patient contact. McKenna notes that there are many studies in which 'researchers have uncovered many patient-centred factors that appear to be positively correlated with a rich [more qualified, less non-qualified] skill mix of qualified staff' and that staff productivity and morale increase in these circumstances. Nevertheless, he notes that since the early 1980 s there has been an increase in the number of non-qualified staff within NHS nursing, a decrease in qualified staff, and an increase in health productivity.

In a review paper, Roberts (1994) discusses the development, training and role of health care assistants (HCAs) and describes the Royal College of Nursing's guidelines for their role. Like McKenna, he acknowledges that implementing new systems of training and assessment can be costly. He suggests that poor definition of an HCA's role within the team can lead to reduced quality of patient care, particularly where their role is task-oriented rather than patientoriented. There is a lack of uniformity in their recruitment and training. He concludes that clarification of these issues would lead to improvements in patient care.

It seems that, despite some findings which suggest quality of patient care may fall, an increasing number of less qualified staff are a fact of life within the current NHS. Studies within 
nursing suggest that clear role definition and a high standard of training for non-qualified staff are important strategies. Physiotherapists should be aware of these issues while bearing in mind that the broader questions of the effectiveness and economics of physiotherapy assistants' work remain unanswered.

The following report pertains to the research project described earlier, in which the first author is the research physiotherapist.

\section{Defining the Assistant's Role}

\section{Method}

The assistant recruited for the research project was a nursing auxiliary with a number of years' experience on a stroke unit. She had not previously worked as a physiotherapy assistant. The research physiotherapist had experience in working with both assistants and stroke patients.

Before the study began, there was a need to define the activities appropriate for the assistant to perform with those patients assigned to her. In order to get an impression of current practice, the views of seven senior physiotherapists within the Trent Region were ascertained. All treated stroke patients and were chosen as a convenience sample because of their clinical responsibilities and geographical location. A semi-structured interview was used as attitudes were being investigated (Fielding, 1993). The research physiotherapist was the interviewer. The physiotherapists were asked which treatment activities they would and would not ask assistants to perform when treating stroke patients' upper limbs. Methods they used to communicate treatment plans were discussed, as were the therapists' opinions on assistants' training needs. The interview ended with an open question allowing the respondents to raise any other issues they considered relevant. Responses were recorded using written notes, upon which content analysis (Sommer and Sommer, 1991) was performed by the authors.

\section{Findings}

Results are reported here in terms of general themes which may be thought-provoking; they do not claim to present a broad or comprehensive picture.

The work environments of interviewees were stroke wards (4), acute medical wards (2), and a neurology out-patient service (1). The ratio of qualified to assistant staff ranged from 5:1 to 1:1. Five interviewees reported that assistants' placements rotated, length of rotations ranging from two to six months.
Among activities considered suitable for delegation to assistants, all mentioned delegating supervision of some form of 'functional activities' such as reaching and dexterity tasks. Most reported that for appropriate patients they would delegate specific inhibitory mobilisations for parts of the arm distal to the shoulder and 'active movement and facilitation' such as gym ball activities. Passive movements, massage, and teaching correct arm posture were each mentioned by more than one interviewee.

Encouraging patients to attend to their arm was mentioned as an important role by two of those interviewed: 'Directing the patient's attention to the area...activating...is a positive thing assistants can do.'

On the whole, it was felt that assistants could most appropriately work with patients who were 'recovering', 'good', or 'late' - described by one as 'patients who can almost do it anyway, but need time to practise'.

Most stated that they would not delegate treatment of those with extreme stroke pathology such as severe spasticity, flaccidity, compensation, perceptual or emotional problems, or pain. Specific shoulder mobilising work was deemed by all but one as unsuitable, and some also mentioned weight bearing through the arm as unsuitable.

Most interviewees were wary about assistants working to facilitate tone or working with patients at the limit of their balance or movement abilities, summarised by one as 'pushing a patient to their edge'.

The complexity of problems associated with the upper limb after stroke led one physiotherapist to say that 'the upper limb is the last thing I'd give an assistant in a way'.

The same interviewee, however, mentioned a number of aspects of upper limb treatment where she did feel assistants had a valid role. The main area of difference between interviewees concerned 'inhibitory mobilisations', some saying that they would not delegate this activity to assistants, others that they would do so after training.

All mentioned that they communicated about treatments by demonstration and explanation as part of physiotherapy sessions with patients. Frequently, supervision was continuous because the physiotherapist and assistant worked in the same room. Some mentioned that the assistant had access to the physiotherapy notes but few said that they gave written treatment plans to the assistant. 
Almost all those interviewed felt that to work in this area, training in normal movement is needed, and they tended to mention practical sessions in this context. Most spoke of teaching about the 'effects of stroke' or mentioned specific movement problems such as subluxed shoulders, spasticity and compensation.

Most also thought training should include basic anatomy and biomechanics and basic handling and positioning techniques. A couple linking this with 'ability to identify when to stop, what patients should and should not be encouraged to do'.

When the interviewees were asked whether they felt there were any other relevant issues, a number of themes arose. These were:

- Limits on use of assistants to their full potential.

- Important qualities of an assistant.

- Good practice in managing assistants.

Limits on use of assistants to their full potential included lack of time for training, mentioned by two therapists, with another two reporting that rotations were too short to allow development of skills. There were concerns about the quality of training: 'They come in on the junior in-service training on background anatomy and physiology but I don't know how much they take in'.

A number seemed to imply a belief that the potential of assistants is underestimated, as illustrated by this comment: 'We shouldn't underestimate what they should be capable of, just because [they've] not had lots of academic training. In neurology it's handling that's important.'

Important qualities in assistants mentioned by some were aptitude and abilities, and by others, experience. Two interviewees remarked that level of experience is not necessarily linked to aptitude. Interest, enthusiasm, and ability to learn were also mentioned.

Understanding of boundaries was an important theme: 'Initiative but with the right perspective...[They need] awareness of the limitations of the role.'

Having correct expectations and knowing your staff was mentioned as important by several, as was the need to give assistants responsibility when treating patients, and a role within the team. 'Level of supervision depends on competence and experience...It's a professional judgement (that's true of supervising juniors too!)' 'They need to have a feeling of positive contribution - involvement in decision making.'

\section{Developing the Assessment and Training Programme}

\section{Method}

Informed by the views of the physiotherapists, a training programme was designed, and is summarised in table 1 . The level of background knowledge, practical skills and insight expected were clarified. A summary of assistant roles and activities, and of the theoretical knowledge to be included in the training, was then written by the research physiotherapist. This document, 'Knowledge and Competencies', is available as a resource for both the physiotherapist and assistant and facilitates clear description of the training and role of the assistant. Topics covered are:

- Functions of the upper limb.

- Upper limb anatomy, physiology and normal movement.

- Effects of stroke on tone, movement and the upper limb.

- Principles of physiotherapy treatment.

- General procedural details of treatments.

- Record keeping.

- Recognising and responding to adverse reactions.

- Moving and handling skills.

A manual of treatment activities was prepared. Almost 40 activity types are included, from which individual regimes are constructed. Two example activities are shown in table 2.

\section{Assessment}

Assessment was used to determine level of knowledge at each stage and to ensure the training was appropriate and effective. Both oral questioning and observation of practice were used.

A semi-structured interview, based on the topics covered in the 'Knowledge and Competencies' document, was used to assess background knowledge before and at the end of formal training. It took about an hour to administer. Criteria and a scale for marking were formulated and were used by the research physiotherapist and an external examiner to score the responses. The external examiner was a senior physiotherapist on the hospital's stroke unit. Examples of questions asked are shown in table 3 and the marking scale is summarised in table 4 .

Competence in practical skills is essential to good treatment of patients, but is more difficult to assess than theoretical knowledge. The National 
Table 1: Summary of assessment and training process

Defining role and treatment activities to be performed

Documenting knowledge and competencies and a treatment manual

Assessment of assistant's initial level of knowledge

Theoretical and practical training sessions

Training and supervision with patients

Reassessment of knowledge and assessment of practical skills

Table 2: Examples of activities described in the assistant's manual. Appropriate modifications to the instructions are added to the individual patient's plan

\begin{tabular}{|c|c|}
\hline & Activity instructions \\
\hline \multicolumn{2}{|c|}{ 'Drooping' or hands towards feet exercise } \\
\hline Goal & $\begin{array}{l}\text { Relax shoulder girdles, scapulae drop forwards. } \\
\text { Relax tight stroke arm }\end{array}$ \\
\hline $\begin{array}{l}\text { Starting } \\
\text { position }\end{array}$ & Upright sitting, hands rest lateral to knees. \\
\hline \multicolumn{2}{|l|}{ Equipment } \\
\hline $\begin{array}{l}\text { Manual } \\
\text { help and } \\
\text { instructions }\end{array}$ & $\begin{array}{l}\text { Patient to drop head, curl spine and drop hands } \\
\text { towards feet. } \\
\text { One hand should not go further than the other. } \\
\text { Hands can lightly touch the legs or hang freely, } \\
\text { Do not hold the position with head down, but } \\
\text { smoothly come up, staying relaxed at the } \\
\text { shoulders. }\end{array}$ \\
\hline Checks & $\begin{array}{l}\text { Ensure both shoulders and neck are relaxed. } \\
\text { Patient goes only as far as comfort allows. } \\
\text { Stop if dizziness occurs. }\end{array}$ \\
\hline \multicolumn{2}{|c|}{ Reaching for a cup and drinking using the stroke arm } \\
\hline Goal & Re-educate normal functional movement. \\
\hline $\begin{array}{l}\text { Starting } \\
\text { position }\end{array}$ & $\begin{array}{l}\text { Sitting at a table with glass half full of water in } \\
\text { front. }\end{array}$ \\
\hline Equipment & $\begin{array}{l}\text { Easiest is hard plastic glass. } \\
\text { Harder is a cup with a handle, or a disposable } \\
\text { soft cup. }\end{array}$ \\
\hline $\begin{array}{l}\text { Manual } \\
\text { help and } \\
\text { instructions }\end{array}$ & $\begin{array}{l}\text { Minimal assistance may be needed. } \\
\text { May guide slightly at hand or correct hunching } \\
\text { abduction of shoulder. } \\
\text { Move the glass further away to progress. }\end{array}$ \\
\hline Checks & $\begin{array}{l}\text { Patient should not hunch shoulder. } \\
\text { Elbow should not cock out to side more than } \\
\text { normal. } \\
\text { Adjust table to a comfortable height for patient. }\end{array}$ \\
\hline
\end{tabular}

Table 3: Some examples of questions from semi-structured interview assessing assistant's level of knowledge

Background anatomy

Can you tell me what sorts of activities we use our arms for in everyday life? Can you show me and name the movements which are possible at the wrist joint?

Background physiology

What do you understand by the term muscle tone?

Pathology

What is spasticity? What is shoulder subluxation?

Communicating with patients

How can you help a patient to learn and remember the treatment and advice given?

Treating patients

How should a patient be taught to care for and position the affected arm and hand? (answered using role play)

Precautions

How do you recognise the signs of a patient becoming too tired during a treatment session?
Table 4: Descriptive scale used in assessments (based on materials developed by Judith Pitt-Brooke of the Nottingham School of Physiotherapy)

A Very good - Could hardly be bettered in the context in which the work is judged.

B Good - Many good features.

C Fair - Adequate and satisfactory level of attainment.

D Weak - Adequate and safe but generally poor.

F Fail - Unsatisfactory, inadequate performance.

Vocational Qualifications (NVQ) concept of 'competence based assessment', primarily carried out in the workplace, was used (CSP, 1994b). Some techniques commonly used when assessing physiotherapy students were also used. At the end of the pilot phase of the study, treatment by the assistant of three patients was observed by the research physiotherapist and the external assessor. This took $3 \frac{1}{2}$ hours. A descriptive scale similar to that summarised in table 4 was used for marking.

The areas of assessment were:

1. Overall competence in the techniques observed.

2. Safety.

3. Rapport with patient.

4. Treatment of patient.

\section{Training}

Training followed the CSP's Guidelines in that it included 'theoretical and practical components reinforced by well supervised practice' (CSP, 1989). It consisted of the following elements.

1. Theory and practical sessions on background anatomy, normal movement and pathology which were videotaped to enable repeated viewing (four hours).

2. Background reading which augmented the training sessions - see table 5 .

\section{Table 5: Background reading given to assistant}

Davies, P M (1985). Steps To Follow, Springer Verlag, Berlin. Introduction, discussion of perceptual problems, 'shoulder hand syndrome'.

Carr, J H and Shepherd, R B (1987). A Motor Relearning Programme for Stroke, Butterworth Heinemann, Oxford. Appendix discussing feedback.

Lynch, M and Grisogono, V (1991). Strokes and Head Injuries, John Murray, London.

Brain damage, hemiplegia and spasticity, physiotherapy treatment.

Moffat, D and Mottram, R (1979). Anatomy and Physiology for Physiotherapists, Blackwell, Oxford. Joints and muscles of the upper limb.

Kapit, $W$ and Elson, L (1977). The Anatomy Colouring Book, Harper and Row, New York.

Upper limb illustrations. 
3. Specific training in treatment techniques $\left(3^{1 / 2}\right.$ hours with normal models, 7 hours with patients). Sessions with normal models were videotaped, and still photographs of many of the treatment techniques were taken, which illustrate the manual.

4. Ongoing supervised practice with patients who are subjects within the study (supervision times will be reported with final study results).

5. Following post-training assessments, a further three hours were spent clarifying issues and techniques.

Treatment techniques were not taught in isolation but in the context of principles such as awareness of whole body posture and movement, and what types of activities should be encouraged and discouraged. Levels of surfaces used, environment and safety issues were considered as were issues of communication, comfort and dignity.

\section{Findings}

The assistant's level of background knowledge as assessed by the semi-structured interview had increased markedly by the end of the training period. She was judged competent in the practical techniques observed. She scored highly on the accuracy of application and the understanding of the techniques used. Reassessment at intervals during the running of the project is planned.

\section{Discussion}

Making decisions about which tasks should be delegated and which patients should be treated by assistants is part of everyday practice for many physiotherapists. Ideally these decisions should be evidence-based but a major obstacle to this is the dearth of experimental research. At present, decisions tend to be made on the basis of guidelines issued by professional bodies, personal opinions, and resource constraints. This results in wide variations in the role and activities of assistants in different work places (eg Saunders, 1995). Opinions also differ as to the type and depth of training appropriate (eg Saunders, 1996; CSP, 1994b).

\section{Making Decisions in This Case}

In the case described above, several factors influenced decisions about the role of the assistant and the depth of training. These included review of the literature, professional guidelines, and opinions of the clinician interviewees and the research physiotherapist. The beliefs and treatment style of the research physiotherapist and the personal char- acteristics of both the physiotherapist and the assistant also affected choices made. The assistant would be working alone and needed enough knowledge to be able to recognise potentially hazardous circumstances. Stroke patients have various disability levels, needing a correspondingly wide range of treatments. Thus it was not sufficient to teach a standard 'recipe' for treatments. Delegation on the basis of simple task assignment may also be detrimental to the quality of patient care (McKenna, 1995). It was thus felt that the quality of care for patients and of job satisfaction for the assistant would be maximised if there was an understanding of why techniques were applied (Mead et al, 1985). The training was nevertheless more technique-based and far narrower than that which physiotherapists undergo. Training was not designed to teach clinical assessment or treatment planning. Further evaluation of the appropriateness of this particular programme will be possible when the full study is complete.

\section{Some Issues for Physiotherapists}

Comments made by the small group of physiotherapists surveyed indicated a respectful and positive attitude to assistants. They suggested that assistants' potential is under-used, and that they are under-trained. Activities the physiotherapists would not wish to delegate tended to be those where safety and skill were important issues, as when handling the shoulder. Thus the physiotherapists had clear views about the work they felt appropriate for assistants, but underlying this was a concern about the insufficiencies of current training.

Appropriate training of assistants is a professional requirement. It must also be ethical and efficient. The increasing numbers of non-qualified workers within the NHS make this a highly relevant issue. Pressures of time and workload make the obligation difficult to meet. Rotation of assistant staff placements may also contribute to inadequate training. NVQ training seems to offer an answer, but it may not always be relevant (Saunders, 1995) as it may be too broad for the department's needs. NVQ training also requires a substantial time commitment by the assistant and the physiotherapist assessor. Alternative programmes may be required.

\section{Applications and Limitations of This Case}

A very specific case has been described and findings are thus limited to a particular context. Further investigations exploring assistants' roles and training in the wide variety of settings in which they work are needed. However, some 
aspects of this package could also be applicable in other clinical settings. Clear definition of role and adequate assessment will facilitate appropriately focused training in both clinical and research fields. In the case described, discussion with other experienced physiotherapists facilitated role definition, and skills in assessing physiotherapy students were translated to assessment of an assistant. Preparing videotaped and written training materials seems efficient as they can be used repeatedly.

Aspects in which the current study differs from the clinical situation must be acknowledged. These include the narrow focus of the assistant's treatment activities. Also unusual is the separation of her group of patients. In treatment of acute stroke, assistants usually augment work the physiotherapist is doing with the same group of patients.

The methodology of the interviews with clinicians could be criticised because the responses were recorded in written form. Taping and transcribing them would have offered greater protection against bias, but would have been prohibitive in time and cost. Our use of a fairly structured schedule may also have limited the range of responses. The aim of the interviews was to gain an impression of current practice; a detailed and highly accurate survey would require more extensive and stringent methodology. The scoring systems used for assessment are by their nature subjective and descriptive. The use of two observers was aimed at improving objectivity as was the fact that they were formulated using materials developed by the Nottingham School of Physiotherapy in its assessment of students.

\section{Areas for Future Investigation}

Open discussion of the controversial issues of the role and training of assistants would be enhanced if more experimental evidence was available. There is a need for broad investigation into what types of work constitute the most clinically effective and cost effective contribution of assistants to patient care. Results of such research could also be used by physiotherapists to argue the case for adequate time and support for training.

\section{Conclusion}

A study of the treatment of stroke patients which is currently in progress involves evaluation of treatments given by both a physiotherapist and an assistant. The need to train the assistant for this study prompted consideration of appropriate therapeutic activities for delegation and the preparation required to perform these. There seems to be no recorded experimental evidence relevant to such issues. Therefore consensus opinion, professional guidelines and requirements of the study guided decisions. Post-training assessment of the assistant's knowledge and practical skills indicated to us that the training was successful. However, experimental evaluation is required both in this specific case and in all areas where assistants contribute to physiotherapeutic management of patients. While it would not be appropriate to generalise from this specific case, we believe that clearly described assessment and training packages such as that described are needed in both the research and clinical fields. The content and depth of any programmes should be carefully designed and clearly argued.

\section{Acknowledgments}

We thank M Appleyard, the physiotherapy assistant, for her continuing hard work. We would like to thank the physiotherapist interviewees, P Hodgson who was the external examiner, and $\mathrm{P}$ Van Vliet, $\mathrm{P}$ Siemonsma, and $\mathrm{N}$ Lincoln who gave valuable advice.

\section{Authors and Contribution}

Ruth Parry MCSP is a research physiotherapist. She developed the assessment and training package discussed in the paper and conducted the interviews in the survey. She is the physiotherapist in the rehabilitation of arm function study.

Catherine Vass MSC RGN is a research nurse. She was involved in the content analysis discussed in the paper, and is the independent assessor for the rehabilitation of arm function study.

This article was received on February 15, 1996, and accepted on September 29, 1996.

\section{Source of Funding}

The rehabilitation of arm function study is a three-year project funded by the NHS Research and Development Programme on Cardiovascular Disease and Stroke.

\section{Address for Correspondence}

Miss Ruth Parry MCSP, Stroke Research Unit, Division of Stroke Medicine, Nottingham City Hospital, Hucknall Rd, Nottingham NG5 1PB.

\section{References}

Chartered Society of Physiotherapy (1989). 'Physiotherapy helpers and community and other support workers', Physiotherapy, 75, 5, 289-291.

Chartered Society of Physiotherapy (1994a). Guidelines for the Management of Physiotherapy Helpers, CSP, London.

Chartered Society of Physiotherapy (1994b). N/SVQs Explained, CSP, London.

College of Occupational Therapists (1996). The Role of Support Workers in the Delivery of Occupational Therapy Services, COT, London.

Fielding, N (1993). 'Qualitative interviewing' in: Gilbert, N (ed) Researching Social Life, Sage, London.

Hirama, H (1994). 'Should certified occupational therapy assistants provide occupational therapy services independently?' American Journal of Occupational Therapy, 48, 9, 840-843.

Lupi-Williams, F (1983). 'The PTA role and function - An analysis in three parts', Clinical Management, 3, 3, 35-38. 
McKenna, $H$ (1995). 'Nursing skill mix substitutions and quality of care: An exploration of assumptions from the research literature', Journal of Advanced Nursing, 21, 452-459.

McNeil, A, Biddulph, D and Walker, J (1990). 'Role of physiotherapy auxiliary personnel in Nova Scotia: A descriptive survey', Physiotherapy Canada, 42, 4, 175-180.

Mead, J, Crawford, M and Wells, J (1985). 'Training for helpers: A multi-disciplinary approach', British Journal of Occupational Therapy, 48, 7, 211-214.

New Zealand Society of Physiotherapists (1981). 'Rules of conduct and a training programmes for hospital physiotherapy aides', New Zealand Journal of Physiotherapy, 9, 25-26.

Roberts, I (1994). 'The health care assistant: Professional supporter or budget necessity?', International Journal of Health Care Quality Assurance, 7, 6, 20-25.

Robinson, A, McCall, M, DePalma, M, Clayton-Krasinski, D, Tingley, S, Simoncelli, S and Harnish, L (1994). 'Physical therapists' perceptions of the roles of the physical therapist assistant', Physical Therapy, 74, 6, 571-582.
Samworth J (1995) 'Skill mix within a community physiotherapy service. A study evaluating the effects of helpers in the Sheffield Community Physiotherapy Service' (unpublished), Community Health Sheffield, Fulwood House, Sheffield.

Saunders, E (1995). 'The role of physiotherapy helpers in outpatient physiotherapy services', Physiotherapy, 81, 7, 384-391.

Saunders, E (1996). 'Managing delegation to physiotherapy assistants: Application of a functional analysis model', Physiotherapy, 82, 4, 246-252.

Sommer and Sommer (1991). A Practical Guide to Behavioural Research Techniques, Oxford University Press, 3rd edn.

Strickland, A (1993). 'National perspective: Response to the report on the study of the role and use of support personnel in the rehabilitation disciplines', Canadian Journal of Occupational Therapy, 60, 228-230.

Walker, A (1995). 'Patient compliance and the placebo effect', Physiotherapy, 81, 3, 120-126.

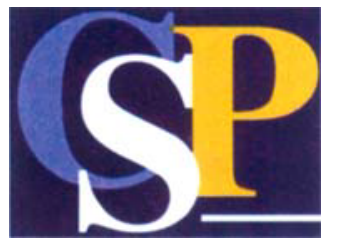

\section{Professional Affairs Department Information Papers}

These papers are all available free of charge (though a stamped addressed envelope is appreciated) from the Professional Affairs Department, CSP, 14 Bedford Row, London WC1R 4ED. Please state clearly which paper is required.

PA1: Reports for Legal Purposes

PA2: Access to Health Records

PA3: Use of NHS Facilities for Private Practice

PA4: Equipment Safety and Product Liability (Consumer Protection Act 1987)

PA5: Patients Seeking Treatment in the Public and Private Sectors

PA6: The Delegation of Tasks to Physiotherapy Assistants and Other Support Workers

PA7: Thinking of Private Practice

PA8: Patient Handling Training

PA9: Manual Handling of Inanimate Loads Training

PA10: Working in the United Kingdom

PA11: Facilitating Exchanges

PA12: Going Abroad - Questions to ask

PA13: Joint Statement of Working Together in Psychophysical Preparation for Childbirth

PA14: Quality Assurance in Health Care - A glossary of terms

PA15: Quality Assurance - Conducting a consumer satisfaction survey

PA16: How to Set Standards

PA17: The Patient's Charter

PA18: Quality Assurance: References for audit
PA19: Pelvic Floor and Vaginal Assessment: Guidance for course tutors and postgraduate physiotherapists

PA20: General Principles of Record Keeping

PA21: Physiotherapists Working Outside the Scope of Physiotherapy Practice

PA22: Accreditation

PA23: Specialisms and Specialists

PA24: Licensing of Acupuncture

PA25: Use of Lasers by Chartered Physiotherapists in Private Practice - The legal position

PA26: Standards of Business Conduct

PA28: Patterns of Health Care Delivery: Managed care information for chartered physiotherapists

PA29: Clinical Physiotherapy Specialist Posts in Out-patient clinics: Guidance for members

PA30: Rationing of Physiotherapy Services

PA31: Use of Injections by Physiotherapists: Interim guide

PA32: Chartered Physiotherapists and Insurance

PA33: Medical Devices Agency

PA34: New NHS Complaints Procedure

PA35: Treatment Involving Manual Handling

PA36: Clinical Guidelines - Reference list

PA37: The Protection and Use of Patient Information 